\title{
Genetic polymorphisms in ataxin-3 and liver cirrhosis risk related to aflatoxin $\mathrm{B} 1$
}

\author{
Xing-Zhizi Wang ${ }^{1, *}$, Xiao-Ying Huang ${ }^{1, *}$, Jin-Guang Yao ${ }^{1, *}$, Chao Wang ${ }^{2}$, Qiang Xia ${ }^{3}$ \\ and Xi-Dai Long ${ }^{1,3,4}$ \\ ${ }^{1}$ Department of Pathology, The Affiliated Hospital of Youjiang Medical University for Nationalities, Baise 533000, China \\ ${ }^{2}$ Department of Digestive Medicine, The Affiliated Hospital of Youjiang Medical University for Nationalities, Baise 533000, \\ China \\ ${ }^{3}$ Department of Liver Surgery, Ren Ji Hospital, School of Medicine, Shanghai Jiao Tong University, Shanghai 200127, China \\ ${ }^{4}$ Guangxi Clinic Research Center of Hepatobiliary Diseases, Baise 533000, China \\ *These authors contributed equally to this work \\ Correspondence to: Xi-Dai Long, email: sjtulongxd@263.net
}

Keywords: ataxin-3; polymorphism; liver cirrhosis; aflatoxin B1; Gerotarget

Received: August 02, 2017 Accepted: November 07, 2017 Epub: February 19, 2018 Published: June 08, 2018

Copyright: Wang et al. This is an open-access article distributed under the terms of the Creative Commons Attribution License 3.0 (CC BY 3.0), which permits unrestricted use, distribution, and reproduction in any medium, provided the original author and source are credited.

\section{ABSTRACT}

Background: Altered expression of ataxin-3 (AT3) can modify DNA repair capacity and is observed in human diseases. The genetic polymorphisms of this gene in aflatoxin B1 (AFB1)-related liver cirrhosis (LC) have not yet been elucidated.

Materials and Methods: We conducted a hospital-based case-control study, including 384 patients with LC and 851 controls without any liver diseases, to assess the association between 264 polymorphisms in AT3 and AFB1-related LC risk. Genotype were tested using TaqMan-PCR or sequencing technique.

Results: We found three differentially distributed SNPs (rs8021276, rs7158733, and rs10146249) via the screening analysis; however, only rs8021276 polymorphism was further identified to modify the risk of LC. Compared with the homozygote of rs8021276 A alleles (rs8021276-AA), the genotypes of rs8021276 G alleles (rs8021276-AG or -GG) increased LC risk (OR: 2.48 and $6.98 ; 95 \%$ CI: 1.84-3.33 and 4.35-11.22, respectively). Significant interactive effects between risk genotypes and AFB1 exposure status were also observed in the joint effects analysis. Additionally, rs8021276 polymorphism was also associated with down-regulation of AT3 mRNA expression and increasing AFB1-DNA adducts in liver tissues with cirrhosis.

Conclusions: These results suggest AT3 polymorphisms may be risk biomarkers of AFB1-related LC, and rs8021276 is a potential candidate.

\section{INTRODUCTION}

Aflatoxin B1 (AFB1) exposure is prevalent in the Bose population and is associated with a variety of clinical consequences $[1,2]$. Some persons with chronic AFB1 exposure are in the diseases-free state; whereas others develop chronic liver damage including liver cirrhosis, which finally develops into hepatocellular carcinoma (HCC) [1-3]. Increasing evidence have shown that persistent exposure with AFB1 can induce liver injury, fibrosis connective tissue proliferation, and ultimately result to liver cirrhosis [4-6]. However, only a minority of lifelong chronic exposed individuals will eventually develop liver cirrhosis, and the cellular and molecular mechanisms of liver cirrhosis pathogenesis are still not completely understood. In the context of chronic liver damage, genetic polymorphisms, such as the singlenucleotide polymorphisms (SNPs), have been considered a risk factor for liver cirrhosis $[7,8]$.

Ataxin-3 (AT3) is an important deubiquitylation enzyme (DUB) encoded by the corresponding gene located on chromosome 14q21 [9]. Increasing evidence have shown that AT3 expression can express more than fifty-six alternatively spliced messenger RNAs (mRNAs) 
and 20 of these spliced mRNAs can translate into corresponding functional proteins. Its full-long expressing product possesses 376 amino acids and 42 kilodaltons of molecular weight $[9,10]$. AT3 protein consists of two functional regions: (1) a globular Josephin domain with deubiquitinating activity in the N-terminal (the 1st to 170th amino acid) and (2) a flexible functional tail in the C-terminal (FFTC) that contains two ubiquitin-interacting motifs (located at the 223th to 240th and the 243th to 260th amino acid, respectively), a casein kinase II site (the 227th to 280th amino acid), nuclear localization signal site (the 282 th to 285 th amino acid), and a polyglutamine structure (the 296th to 317th amino acid) [9, 11]. Functionally, AT3 involves in protein homeostasis and degradation, myogenesis, cytoskeleton and transcription regulation, and cell cycle and death [7,9-12]. In the past decades, the dysregulation of AT3 has been reported to play an important role in the pathogenesis of human chronic damage diseases such as a preponderance of evidence has implicated aberrant, gastric cancer, and breast cancer [10, 13-16]. Despite the collected data, the association between the genetic variables in the AT3 gene and AFB1related chronic disease liver cirrhosis is still unclear. Here, we investigated whether genetic SNPs in this gene affect the risk of liver cirrhosis correlated with AFB1 exposure.

\section{RESULTS}

\section{Baseline features of study subjects}

(Table 1) summarized the baseline features (including demographic characteristics and AFB1 exposure information) of cases with liver cirrhosis and controls. Higher serum AFB1 albumin adducts (AAAs) were observed in the individuals with liver cirrhosis than these without liver cirrhosis $(1.48 \pm 0.32$ vs. $2.40 \pm 0.91$ ln fmol/mg). Results from relative risk analyses based on multivariable regression model further showed that these individuals with medium AFB1 exposure featured a 3.59time risk of liver cirrhosis compared to those with low exposure; whereas those with high exposure would face higher risk [adjusted odd ratio (OR), 7.74; 95\% confidence intervals (CI), 5.51-10.87]. This indicates that the risk of liver cirrhosis was significantly positively correlated with the levels of AFB1 exposure. There was not significant difference for other baseline features.

\section{AT3 rs8021276 polymorphism correlated with liver cirrhosis risk}

According to the criteria of SNP selection, 264 common SNPs in the AT3 gene were tested in the screening groups. Analysis of the selected SNPs revealed the genotypic distributions in the control individuals were in Hardy-Weinberg equilibrium (data not shown). Among these selected SNPs, there SNPs (rs8021276, rs7158733, and rs10146249) were observed to significantly associate with liver cirrhosis risk in initial screening group (Table 2). Among individuals in the validation set, only rs8021276 significantly modified the risk of liver cirrhosis $(\mathrm{OR}=$ $\left.3.09,95 \% \mathrm{CI}=2.27-4.19, P=5.33 \times 10^{-13}\right)$ according to the significance threshold $\left(\alpha_{\text {correct }}=1.87 \times 10^{-4}\right)$. In the merged analyses of the screening and validation group (Table 2), the relative risk for liver cirrhosis among those with heterozygotes of rs8021276 A and G alleles (rs8021276-AG) versus those homozygotes of rs8021276 $\mathrm{G}$ alleles (rs8021276-GG) was 2.48 (1.84-3.33). The corresponding risk value for those homozygotes of rs8021276 G alleles (rs8021276-GG) was 6.98 (4.3511.22). Thus, the risk of liver cirrhosis was positively related to the number of rs $8021276 \mathrm{G}$ alleles.

To explore whether the matching variables (including age, gender, ethnicity, drinking and smoking status, and HBV and HCV infection status) affects AT3 rs8021276 polymorphism modifying liver cirrhosis, we finished a series of stratified analyses according to these matching variables (Table 3). Similar risk significance was found among these different stratified variables, with an about 3.5-time risk value for rs8021276-AG/ GG. Interactive analyses based on likelihood ratio tests further proved that matching variables did not affect AT3 rs8021276 polymorphism modifying liver cirrhosis risk $\left(P_{\text {interact }}>0.05\right)$.

\section{Interaction between AT3 rs8021276 polymorphism and AFB1 exposure}

To explore the relationship between AFB1 exposure status and AT3 rs8021276 polymorphism in the risk for liver cirrhosis, we accomplished a joint analysis of AT3 rs8021276 genotypes and AFB1 exposure using individuals with both rs8021276-AA and low level of AFB1 exposure as a reference $(\mathrm{OR}=1)$ (Table 4). The results indicated that higher levels of AFB1 exposure gradually increased liver cirrhosis risk (adjusted OR, from 1 to 6.30 among these with rs8021276-AA); the risk significance was more noticeable among subjects with the risk genotypes of AT3 rs8021276 (adjusted OR, from 1.88 to 11.46 for rs8021276-AG and from 4.27 to 34.01 for rs $8021276-\mathrm{GG}$, respectively). This interaction of genotypes and AFB1 exposure was multiplicative according to gene-environment interaction formula $\left[\mathrm{OR}_{\mathrm{eg}}\right.$ $\left.>\left(\mathrm{OR}_{\mathrm{eg}}, \times \mathrm{OR}_{\mathrm{e}, \mathrm{g}}\right)\right][17]$.

\section{AT3 rs8021276 polymorphism affected AT3 expression and AFB1-DNA adduct levels}

To investigate whether the AT3 rs8021276 polymorphism affected the function of AT3, we conducted a relevant analysis between different genotypes of AT3 rs8021276 polymorphism and AT3 expression using immunohistochemistry (IHC) (Figure 1A-1D). We 
Table 1: Demographic and etiologic characteristics of study subjects

\begin{tabular}{|c|c|c|c|c|c|c|c|}
\hline \multirow{2}{*}{ Variable } & \multicolumn{2}{|c|}{ Screening stage } & \multicolumn{2}{|c|}{ Validation stage } & \multicolumn{3}{|c|}{ Validation stage } \\
\hline & Controls & $\mathbf{L C s}$ & Controls & LCs & Controls & $\mathrm{LCs}$ & OR $\left(95 \% \mathrm{CI} / P_{\text {trend }}\right)^{\mathrm{a}}$ \\
\hline Total & 100 & 100 & 751 & 284 & 851 & 384 & \\
\hline \multicolumn{8}{|l|}{ Age (yrs) } \\
\hline$\leq 49$ & 54 & 54 & 402 & 150 & 456 & 204 & Reference \\
\hline$>49$ & 46 & 46 & 349 & 134 & 395 & 180 & $1.07(0.83-1.40 / 0.59)$ \\
\hline \multicolumn{8}{|l|}{ Gender } \\
\hline Male & 76 & 76 & 568 & 213 & 644 & 289 & Reference \\
\hline Female & 24 & 24 & 183 & 71 & 207 & 95 & $1.32(0.90-1.93 / 0.16)$ \\
\hline \multicolumn{8}{|l|}{ Ethnicity } \\
\hline Han & 51 & 51 & 377 & 142 & 428 & 193 & Reference \\
\hline Zhuang & 49 & 49 & 374 & 142 & 423 & 191 & $0.99(0.77-1.29 / 0.98)$ \\
\hline \multicolumn{8}{|c|}{ Smoking status } \\
\hline No & 52 & 52 & 390 & 132 & 442 & 184 & Reference \\
\hline Yes & 48 & 48 & 361 & 152 & 409 & 200 & $1.34(0.76-2.38 / 0.31)$ \\
\hline \multicolumn{8}{|c|}{ Drinking status } \\
\hline No & 49 & 49 & 364 & 129 & 413 & 178 & Reference \\
\hline Yes & 51 & 51 & 387 & 155 & 438 & 206 & $1.10(0.81-1.44 / 0.75)$ \\
\hline \multicolumn{8}{|l|}{$\mathrm{HBsAg}$} \\
\hline Negative & 62 & 62 & 462 & 168 & 524 & 230 & Reference \\
\hline Positive & 38 & 38 & 289 & 116 & 327 & 154 & $1.08(0.81-1.44 / 0.61)$ \\
\hline \multicolumn{8}{|l|}{ Anti-HCV } \\
\hline Negative & 90 & 90 & 673 & 248 & 763 & 338 & Reference \\
\hline Positive & 10 & 10 & 78 & 36 & 88 & 46 & $1.11(0.71-1.74 / 0.64)$ \\
\hline \multicolumn{8}{|c|}{ AFB1 exposure ${ }^{b}$} \\
\hline Low & 65 & 27 & 478 & 77 & 543 & 104 & Reference \\
\hline Medium & 25 & 38 & 189 & 107 & 214 & 145 & $\begin{array}{c}3.59(2.65-4.84 / 8.54 \times \\
\left.10^{-17}\right)\end{array}$ \\
\hline High & 10 & 35 & 84 & 100 & 94 & 135 & $\begin{array}{c}7.74(5.51-10.87 / 4.46 \times \\
\left.10^{-32}\right)\end{array}$ \\
\hline
\end{tabular}

${ }^{a} \mathrm{OR}$ conditional on matched set.

${ }^{b}$ The mean \pm S.D. level of AFB1-album adducts is $1.48 \pm 0.32 \mathrm{ln} \mathrm{fmol} / \mathrm{mg}$ for controls and $2.40 \pm 0.91 \mathrm{ln} \mathrm{fmol} / \mathrm{mg}$ for cases with LC, respectively.

observed that these liver cirrhosis cases with different AT3 rs8021276 genotypes featured different expression levels of AT3 protein. Represent IHC images showed this expression difference (Figure 1A-1C). To analyze, the levels of AT3 protein expression was classed into low (IRS, <4), medium (IRS, 4-8), and high expression (IRS, $>8$ ), according to IHC scores of IRS systems [18]. Results from spearman's correlation analyses proved that the genotypes of AT3 rs8021276 was significantly negatively associated with the levels of AT3 protein $(r=$ $-0.25, P=7.30^{\prime} 10^{-7}$ ) (Figure 1D). Similar results were observed in the analyses of AT3 mRNA expression and genotypes (Figure 1E). Next, we investigated the effects of AT3 rs8021276 polymorphism on the amount of AFB1DNA adducts in the liver tissues with cirrhosis using comparative enzyme-linked immunosorbent assay and found that this polymorphism can modify the amount of DNA adducts (means \pm S.D., $1.51 \pm 1.23 \mu \mathrm{mol} / \mathrm{mol}$ DNA for rs8021276-AA, $2.09 \pm 1.18 \mu \mathrm{mol} / \mathrm{mol}$ DNA for $\mathrm{rs} 8021276-\mathrm{AG}$, and $3.92 \pm 1.81 \mu \mathrm{mol} / \mathrm{mol} \mathrm{DNA}$ for rs8021276-GG, respectively, $\left.P=5.61 \times 10^{-4}\right)($ Figure $1 \mathrm{~F})$. Taken together, these results were indicative of AT3 rs8021276 polymorphism modulating AT3 expression and the corresponding functions. 
Table 2: Ataxin-3 polymorphisms and liver cirrhosis (LC) risk

\begin{tabular}{|c|c|c|c|c|c|c|c|c|c|}
\hline \multirow[b]{2}{*}{ SNP } & \multicolumn{3}{|c|}{ Screening set } & \multicolumn{3}{|c|}{ Validation set } & \multicolumn{3}{|c|}{ Merge set } \\
\hline & $\begin{array}{l}\text { Controls } \\
(n=100)\end{array}$ & $\begin{array}{c}\text { LCs } \\
(n=100)\end{array}$ & OR $\left(95 \% \mathrm{CI} / \boldsymbol{P}_{\text {trend }}\right)^{\mathrm{a}}$ & $\begin{array}{l}\text { Controls } \\
(n=751)\end{array}$ & $\begin{array}{c}\text { LCs } \\
(n=284)\end{array}$ & OR $\left(95 \% \mathrm{CI} / \boldsymbol{P}_{\text {trend }}\right)^{\mathrm{a}}$ & $\begin{array}{l}\text { Controls } \\
(n=851)\end{array}$ & $\begin{array}{c}\text { LCs } \\
(n=384)\end{array}$ & OR $\left(95 \% \mathrm{CI} / P_{\text {trend }}\right)^{\mathrm{a}}$ \\
\hline \multicolumn{10}{|l|}{ rs8021276 } \\
\hline AA & 72 & 43 & Reference & 543 & 120 & Reference & 615 & 163 & Reference \\
\hline $\mathrm{AG}$ & 24 & 35 & $\begin{array}{c}2.97(1.43-6.16 / \\
\left.3.52 \times 10^{-3}\right)\end{array}$ & 178 & 100 & $\begin{array}{c}2.45(1.75-3.42 / \\
\left.1.417 \times 10^{-7}\right)\end{array}$ & 202 & 135 & $2.48\left(1.84-3.33 / 2.00 \times 10^{-9}\right)$ \\
\hline GG & 4 & 22 & $\begin{array}{c}11.92(3.42- \\
\left.41.55 / 9.97 \times 10^{-5}\right)\end{array}$ & 30 & 64 & $\begin{array}{c}6.54(3.85-11.10 / \\
\left.3.49 \times 10^{-12}\right)\end{array}$ & 34 & 86 & $6.98\left(4.35-11.22 / 9.27 \times 10^{-16}\right)$ \\
\hline $\mathrm{AG} / \mathrm{GG}$ & 28 & 57 & $\begin{array}{c}4.16(2.11-8.18 / \\
\left.3.62 \times 10^{-5}\right)\end{array}$ & 208 & 164 & $\begin{array}{c}3.09(2.27-4.19 / \\
\left.5.33 \times 10^{-13}\right)\end{array}$ & 236 & 221 & $3.17\left(2.42-4.16 / 8.08 \times 10^{-17}\right)$ \\
\hline \multicolumn{10}{|l|}{ rs7158733 } \\
\hline GG & 57 & 32 & Reference & 345 & 112 & Reference & 402 & 144 & Reference \\
\hline GT & 30 & 35 & $\begin{array}{c}3.59(1.62-7.99 / \\
\left.1.72 \times 10^{-3}\right)\end{array}$ & 242 & 97 & $\begin{array}{c}1.25(0.89-1.75 / \\
0.21)\end{array}$ & 272 & 132 & $1.41(1.014-1.91 / 0.03)$ \\
\hline $\mathrm{TT}$ & 13 & 33 & $\begin{array}{c}6.59(2.57- \\
\left.16.88 / 8.57 \times 10^{-5}\right)\end{array}$ & 164 & 75 & $\begin{array}{c}1.38(0.95-2.00 \\
/ 0.10)\end{array}$ & 177 & 108 & $1.70\left(1.22-2.37 / 1.78 \times 10^{-3}\right)$ \\
\hline GT/TT & 43 & 68 & $\begin{array}{c}4.50(2.18-9.31 / \\
\left.4.98 \times 10^{-5}\right)\end{array}$ & 406 & 172 & $\begin{array}{c}1.30(0.96-1.75 / \\
0.09)\end{array}$ & 449 & 240 & $1.52\left(1.17-1.99 / 2.03 \times 10^{-3}\right)$ \\
\hline \multicolumn{10}{|l|}{ rs10146249 } \\
\hline $\mathrm{CC}$ & 46 & 20 & Reference & 292 & 93 & Reference & 338 & 113 & Reference \\
\hline $\mathrm{CA}$ & 41 & 48 & $\begin{array}{c}3.08(1.47-6.43 / \\
\left.2.76 \times 10^{-3}\right)\end{array}$ & 288 & 141 & $\begin{array}{c}1.72(1.23-2.40 / \\
\left.1.40 \times 10^{-3}\right)\end{array}$ & 329 & 189 & $1.96\left(1.45-2.64 / 1.26 \times 10^{-4}\right)$ \\
\hline AA & 13 & 32 & $\begin{array}{c}5.77(2.31- \\
\left.14.37 / 1.59 \times 10^{-4}\right)\end{array}$ & 171 & 50 & $\begin{array}{c}1.20(0.78-1.83 \\
/ 0.41)\end{array}$ & 184 & 82 & $1.67\left(1.16-2.41 / 5.80 \times 10^{-3}\right)$ \\
\hline CA/AA & 54 & 80 & $\begin{array}{c}3.74(1.87-7.49 / \\
\left.1.86 \times 10^{-4}\right)\end{array}$ & 459 & 191 & $\begin{array}{c}1.54(1.13-2.09 / \\
\left.6.24 \times 10^{-3}\right)\end{array}$ & 513 & 271 & $1.86\left(1.41-2.46 / 1.58 \times 10^{-3}\right)$ \\
\hline
\end{tabular}

${ }^{\mathrm{a}} \mathrm{OR}$ conditional on matched set.

\section{DISCUSSION}

In this study, we investigated the correlation between the genetic SNPs in the AT3 gene and liver cirrhosis risk among the Bose population who featured different degrees of AFB1 exposure. We found that AT3 rs8021276 polymorphism increased liver cirrhosis risk $(\mathrm{OR}=2.48$ for rs8021276-AG; 6.98 for rs8021276GG). Furthermore, this polymorphism significantly interacted with environmental factor AFB1 exposure in the pathogenesis of liver cirrhosis. These results indicate that AT3 rs8021276 polymorphism may have functional significance in the pathogenesis of AFB1-related liver cirrhosis.

In China, more than ninety percent of liver cirrhosis results from chronic infection of hepatitis virus $\mathrm{B}$ (HBV) and $\mathrm{C}(\mathrm{HCV})$ [19-21]. A decrease in the frequency of hepatic virus infection as a major cause of this disease and an increase in the number of cases with liver cirrhosis caused by other causes (including AFB1) have recently been noted in China. AFB1 is an important chemical carcinogen that exerts its carcinogenicity through its metabolic activation to the reactive AFB1 8,9-exoepoxide by phase 1 cytochrome P450 monooxygenases [1, 22]. The reactive epoxide can bind to DNA and induce different degrees of DNA damage including adduction formation, and gene mutation $[1,2]$. Our present study displayed that higher level of AFB1 was observed among these individuals with liver cirrhosis than among those without liver cirrhosis. This increasing exposure of AFB1 significantly affected the risk of liver cirrhosis, suggesting that AFB1 might play a crucial role in liver cirrhosis developing. In support of our findings, recent several studies have exhibited that the consumption of AFB1 can induce liver injury, inflammatory cell infiltration, fibrosis tissue proliferation, periportal fibrosis, and tissue cirrhosis $[4,5,22-24]$. The underlying mechanism of AFB1induced liver cirrhosis remains unclear. However, some evidence from genetic susceptibility has recently been noted [25-28].

AT3 is well known for its role in the proteasomal protein degradation pathway, the maintenance of $\mathrm{Ub}$ recycling, and regulation of transcription via its deubiqutinating function. Previously, studies have suggested that the dysregulation of AT3 may involve in the pathogenesis of some human diseases including neurodegenerative disease and tumors [10, 13-16]. For example, more than 52 glutamines resulting from mutative expansion in the polyglutamine region of the C-terminus of AT3 protein will result in neurodegeneration and ultimately cause spinocerebellar ataxia $3[7,9,10,12]$. Through a clinic-pathological study, Zeng et al., found that AT3 protein and mRNA expression was lower in tumor tissues of gastric cancer than in peritumor tissues, and this down-regulating expression significantly affected clinicpathological features of gastric cancer [14]. Sacco, et al. 
Table 3: Ataxin-3 (AT3) rs8021276 polymorphism and liver cirrhosis (LC) risk stratified by matching factors

\begin{tabular}{|c|c|c|c|c|c|c|c|}
\hline \multirow[b]{2}{*}{ Variable } & \multirow[b]{2}{*}{ AT3 } & \multicolumn{2}{|c|}{$\begin{array}{l}\text { Controls } \\
(n=851)\end{array}$} & \multicolumn{2}{|c|}{$\begin{array}{c}\text { LCs } \\
(n=384)\end{array}$} & \multirow[b]{2}{*}{ OR $(95 \% \text { CI })^{\mathrm{i}}$} & \multirow[b]{2}{*}{$\boldsymbol{P}_{\text {trend }}$} \\
\hline & & $n$ & $\%$ & $n$ & $\%$ & & \\
\hline Age $(y r s)^{a}$ & rs8021276 & & & & & & \\
\hline \multirow[t]{4}{*}{$\leq 49$} & AA & 330 & 72.4 & 88 & 43.1 & Reference & \\
\hline & $\mathrm{AG}$ & 109 & 23.9 & 73 & 35.8 & $2.52(1.72-3.68)$ & $1.76 \times 10^{-6}$ \\
\hline & GG & 17 & 3.7 & 43 & 21.1 & $9.50(5.17-17.47)$ & $4.32 \times 10^{-13}$ \\
\hline & $\mathrm{AG} / \mathrm{GG}^{\mathrm{h}}$ & 126 & 27.6 & 116 & 56.9 & $3.46(2.45-4.89)$ & $1.78 \times 10^{-12}$ \\
\hline \multirow[t]{4}{*}{$>49$} & AA & 285 & 72.2 & 75 & 41.7 & Reference & \\
\hline & $\mathrm{AG}$ & 93 & 23.5 & 62 & 34.4 & $2.55(1.69-3.84)$ & $8.17 \times 10^{-6}$ \\
\hline & GG & 17 & 4.3 & 43 & 23.9 & $9.66(5.21-17.92)$ & $5.96 \times 10^{-13}$ \\
\hline & AG/GG & 110 & 27.8 & 105 & 58.3 & $3.65(2.52-5.28)$ & $7.09 \times 10^{-12}$ \\
\hline Gender $^{b}$ & rs8021276 & & & & & & \\
\hline \multirow[t]{4}{*}{ Male } & $\mathrm{AA}$ & 465 & 72.2 & 123 & 42.6 & Reference & \\
\hline & $\mathrm{AG}$ & 152 & 23.6 & 102 & 35.3 & $2.53(1.84-3.49)$ & $1.26 \times 10^{-6}$ \\
\hline & GG & 27 & 4.2 & 64 & 22.1 & $9.15(5.57-15.02)$ & $2.16 \times 10^{-18}$ \\
\hline & AG/GG & 179 & 27.8 & 166 & 57.4 & $3.51(2.62-4.69)$ & $3.67 \times 10^{-17}$ \\
\hline \multirow[t]{4}{*}{ Female } & AA & 150 & 72.5 & 40 & 42.1 & Reference & \\
\hline & $\mathrm{AG}$ & 50 & 24.2 & 33 & 34.7 & $2.49(1.42-4.38)$ & $1.48 \times 10^{-3}$ \\
\hline & GG & 7 & 3.4 & 22 & 23.2 & $11.69(4.66-29.35)$ & $1.63 \times 10^{-7}$ \\
\hline & $\mathrm{AG} / \mathrm{GG}$ & 57 & 27.5 & 55 & 57.9 & $3.64(2.19-6.07)$ & $6.68 \times 10^{-7}$ \\
\hline Race $^{c}$ & rs8021276 & & & & & & \\
\hline \multirow[t]{4}{*}{ Han } & $\mathrm{AA}$ & 303 & 70.8 & 78 & 40.4 & Reference & \\
\hline & $\mathrm{AG}$ & 102 & 23.8 & 65 & 33.7 & $2.47(1.66-3.68)$ & $8.51 \times 10^{-6}$ \\
\hline & GG & 23 & 5.4 & 50 & 25.9 & $8.47(4.86-14.73)$ & $4.30 \times 10^{-14}$ \\
\hline & AG/GG & 125 & 29.2 & 115 & 59.6 & $3.57(2.51-5.10)$ & $2.06 \times 10^{-12}$ \\
\hline \multirow[t]{4}{*}{ Zhuang } & $\mathrm{AA}$ & 312 & 73.8 & 85 & 44.5 & Reference & \\
\hline & $\mathrm{AG}$ & 100 & 23.6 & 70 & 36.6 & $2.57(1.74-3.79)$ & $1.92 \times 10^{-6}$ \\
\hline & GG & 11 & 2.6 & 36 & 18.8 & $11.99(5.85-24.60)$ & $1.24 \times 10^{-11}$ \\
\hline & AG/GG & 111 & 26.2 & 106 & 55.5 & $3.51(2.45-5.02)$ & $6.83 \times 10^{-12}$ \\
\hline Smoking ${ }^{\mathrm{d}}$ & rs8021276 & & & & & & \\
\hline \multirow[t]{4}{*}{ No } & AA & 332 & 75.1 & 95 & 46.6 & Reference & \\
\hline & $\mathrm{AG}$ & 98 & 22.2 & 73 & 35.8 & $2.29(1.22-4.68)$ & $2.86 \times 10^{-9}$ \\
\hline & GG & 12 & 2.7 & 36 & 17.6 & $7.12(3.51-16.44)$ & $6.22 \times 10^{-13}$ \\
\hline & AG/GG & 110 & 24.9 & 109 & 53.4 & $3.37(2.03-5.29)$ & $2.47 \times 10^{-15}$ \\
\hline \multirow[t]{4}{*}{ Yes } & AA & 283 & 69.2 & 68 & 37.8 & Reference & \\
\hline & $\mathrm{AG}$ & 104 & 25.4 & 62 & 34.4 & $1.92(1.29-2.85)$ & $1.24 \times 10^{-3}$ \\
\hline & GG & 22 & 5.4 & 50 & 27.8 & $7.31(4.19-12.74)$ & $2.26 \times 10^{-12}$ \\
\hline & $\mathrm{AG} / \mathrm{GG}$ & 126 & 30.8 & 112 & 62.2 & $3.26(2.42-4.05)$ & $3.78 \times 10^{-9}$ \\
\hline Drinking ${ }^{\mathrm{e}}$ & rs 8021276 & & & & & & \\
\hline \multirow[t]{3}{*}{ No } & AA & 295 & 71.4 & 73 & 41.0 & Reference & \\
\hline & $\mathrm{AG}$ & 99 & 24.0 & 60 & 33.7 & $2.45(1.63-3.70)$ & $1.90 \times 10^{-5}$ \\
\hline & GG & 19 & 4.6 & 45 & 25.3 & $9.75(5.37-17.70)$ & $7.32 \times 10^{-14}$ \\
\hline
\end{tabular}




\begin{tabular}{|c|c|c|c|c|c|c|c|}
\hline \multirow{5}{*}{ Yes } & $\mathrm{AG} / \mathrm{GG}$ & 118 & 28.6 & 105 & 59.0 & $3.61(2.50-5.21)$ & $7.66 \times 10^{-12}$ \\
\hline & $\mathrm{AA}$ & 320 & 73.1 & 90 & 43.7 & Reference & \\
\hline & $\mathrm{AG}$ & 103 & 23.5 & 75 & 36.4 & $2.59(1.77-3.78)$ & $8.35 \times 10^{-7}$ \\
\hline & GG & 15 & 3.4 & 41 & 19.9 & $9.72(5.15-18.36)$ & $2.42 \times 10^{-12}$ \\
\hline & $\mathrm{AG} / \mathrm{GG}$ & 118 & 26.9 & 116 & 56.3 & $3.47(2.47-4.95)$ & $1.55 \times 10^{-12}$ \\
\hline $\mathrm{HBsAg}^{\mathrm{f}}$ & rs8021276 & & & & & & \\
\hline \multirow[t]{4}{*}{ Negative } & AA & 377 & 71.9 & 96 & 41.7 & Reference & \\
\hline & $\mathrm{AG}$ & 125 & 23.9 & 84 & 36.5 & $2.62(1.85-3.77)$ & $9.08 \times 10^{-8}$ \\
\hline & GG & 22 & 4.2 & 50 & 21.7 & $8.92(5.15-15.46)$ & $5.71 \times 10^{-15}$ \\
\hline & $\mathrm{AG} / \mathrm{GG}$ & 147 & 28.1 & 134 & 58.3 & $3.58(2.59-4.95)$ & $1.22 \times 10^{-14}$ \\
\hline \multirow[t]{4}{*}{ Positive } & $\mathrm{AA}$ & 238 & 72.8 & 67 & 43.5 & Reference & \\
\hline & $\mathrm{AG}$ & 77 & 23.5 & 51 & 33.1 & $2.35(1.51-3.68)$ & $1.67 \times 10^{-4}$ \\
\hline & GG & 12 & 3.7 & 36 & 23.4 & $10.65(5.25-21.60)$ & $5.63 \times 10^{-11}$ \\
\hline & $\mathrm{AG} / \mathrm{GG}$ & 89 & 27.2 & 87 & 56.5 & $3.47(2.33-5.19)$ & $1.17 \times 10^{-9}$ \\
\hline Anti-HCV & rs8021276 & & & & & & \\
\hline \multirow[t]{4}{*}{ Negative } & AA & 552 & 72.3 & 143 & 42.3 & Reference & \\
\hline & $\mathrm{AG}$ & 181 & 23.7 & 117 & 34.6 & $2.50(1.86-3.36)$ & $1.50 \times 10^{-9}$ \\
\hline & GG & 30 & 3.9 & 78 & 23.1 & $10.03(6.34-15.89)$ & $7.92 \times 10^{-23}$ \\
\hline & $\mathrm{AG} / \mathrm{GG}$ & 211 & 27.7 & 195 & 57.7 & $3.57(2.73-4.66)$ & $1.33 \times 10^{-20}$ \\
\hline \multirow[t]{4}{*}{ Positive } & AA & 63 & 71.6 & 20 & 43.5 & Reference & \\
\hline & $\mathrm{AG}$ & 21 & 23.9 & 18 & 39.1 & $2.70(1.21-6.04)$ & 0.02 \\
\hline & GG & 4 & 4.5 & 8 & 17.4 & $6.17(1.67-22.80)$ & $6.31 \times 10^{-3}$ \\
\hline & $\mathrm{AG} / \mathrm{GG}$ & 25 & 28.4 & 26 & 56.5 & $3.25(15.4-6.86)$ & $1.92 \times 10^{-3}$ \\
\hline
\end{tabular}

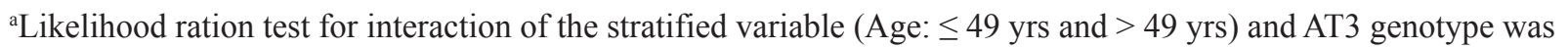
calculated as test for the heterogeneity of ORs across strata $\left(P_{\text {interaction }}=0.722\right)$.

${ }^{b}$ Likelihood ration test for interaction of the stratified variable (female and male) and AT3 genotype was calculated as test for the heterogeneity of ORs across strata $\left(P_{\text {interaction }}=0.793\right)$.

'Likelihood ration test for interaction of the stratified variable (Han and Zhuang) and AT3 genotype was calculated as test for the heterogeneity of ORs across strata $\left(P_{\text {interaction }}=0.935\right)$.

${ }^{\mathrm{d}}$ Likelihood ration test for interaction of the stratified variable (smoking status: no and yes) and AT3 genotype was calculated as test for the heterogeneity of ORs across strata $\left(P_{\text {interaction }}=0.643\right)$.

${ }^{e}$ Likelihood ration test for interaction of the stratified variable (drinking status: no and yes) and AT3 genotype was calculated as test for the heterogeneity of ORs across strata $\left(P_{\text {interaction }}=0.764\right)$.

fLikelihood ration test for interaction of the stratified variable (HBsAg-negative and positive) and AT3 genotype was calculated as test for the heterogeneity of ORs across strata $\left(P_{\text {interaction }}=0.894\right)$.

${ }^{g}$ Likelihood ration test for interaction of the stratified variable (anti-HCV-negative and positive) and AT3 genotype was calculated as test for the heterogeneity of ORs across strata $\left(P_{\text {interaction }}=0.793\right)$.

${ }^{\mathrm{h}} \mathrm{AG} / \mathrm{GG}$ represented the genotypes with AT3 rs8021276 G allele.

iOR conditional on matched set.

[13] and Ge, et al. [29], reported that the dysregulation of AT3 involved in the tumorigenesis of lung cancer and breast cancer. Our data also imply that genetic variants of AT3 promote the pathogenesis of liver cirrhosis. Taken together, these data are indicative of the vital role of AT3 gene in some human diseases.

Until now, over 2,000 genetic SNPs have been identified in the AT3 gene (SNP database, PubMed), some of which have reported to correlate with human diseases [30]. In the first stage of this study, a total of 264 known SNPs were selected for elucidating potential effects of genetic SNPs in the AT3 on liver cirrhosis risk. This was done mainly because the genetic variants may affect the structure and expression of AT3, and potentially involve in liver cirrhosis pathogenesis. Of these selected SNPs, only one (rs8021276) was identified to increased liver cirrhosis risk through two stage analyses (namely the screening stage and the validation stage). Furthermore, the rs 8021276 was also observed to multiplicatively interact with the levels of AFB1 exposure in the pathogenesis of liver cirrhosis. Together, these data indicate that AT3 rs8021276 polymorphism may be a vital 
Table 4: Joint effects of AFB1 exposure and rs8021276 polymorphism on liver cirrhosis (LC) risk

\begin{tabular}{|c|c|c|c|c|c|c|}
\hline \multirow{2}{*}{$\begin{array}{l}\text { AFB1 exposure } \\
\text { level/Genotype }\end{array}$} & \multicolumn{2}{|c|}{$\begin{array}{l}\text { Controls } \\
(n=851)\end{array}$} & \multicolumn{2}{|c|}{$\begin{array}{c}\text { LCs } \\
(n=384)\end{array}$} & \multirow[b]{2}{*}{ OR $(9 \% \text { CI })^{\mathrm{a}}$} & \multirow[b]{2}{*}{$\boldsymbol{P}$} \\
\hline & $n$ & $\%$ & $n$ & $\%$ & & \\
\hline Low/AA & 398 & 46.8 & 57 & 14.8 & Reference & \\
\hline $\mathrm{AG}$ & 134 & 15.7 & 36 & 9.4 & $1.88(1.18-2.98)$ & $7.43 \times 10^{-3}$ \\
\hline GG & 11 & 1.3 & 11 & 2.9 & $4.27(1.92-9.50)$ & $1.52 \times 10^{-5}$ \\
\hline $\mathrm{AG} / \mathrm{GG}^{\mathrm{b}}$ & 145 & 17.0 & 47 & 12.2 & $2.27(1.47-3.48)$ & $1.98 \times 10^{-4}$ \\
\hline Medium/AA & 156 & 18.3 & 51 & 13.3 & $2.28(1.50-3.48)$ & $1.20 \times 10^{-4}$ \\
\hline $\mathrm{AG}$ & 43 & 5.1 & 58 & 15.1 & $9.42(5.82-15.26)$ & $7.93 \times 10^{-20}$ \\
\hline GG & 15 & 1.8 & 36 & 9.4 & $16.75(8.63-32.52)$ & $8.24 \times 10^{-17}$ \\
\hline $\mathrm{AG} / \mathrm{GG}$ & 58 & 6.8 & 94 & 24.5 & $11.32(7.37-17.38)$ & $1.54 \times 10^{-28}$ \\
\hline High/AA & 61 & 7.2 & 55 & 14.3 & $6.30(3.98-9.96)$ & $3.51 \times 10^{-15}$ \\
\hline $\mathrm{AG}$ & 25 & 2.9 & 41 & 10.7 & $11.46(6.48-20.26)$ & $4.90 \times 10^{-17}$ \\
\hline GG & 8 & 0.9 & 39 & 10.2 & $34.01(15.13-76.43)$ & $1.41 \times 10^{-17}$ \\
\hline $\mathrm{AG} / \mathrm{GG}$ & 33 & 3.9 & 80 & 20.8 & $16.93(10.36-27.68)$ & $1.58 \times 10^{-29}$ \\
\hline
\end{tabular}

${ }^{\mathrm{a}} \mathrm{OR}$ conditional on matched set.

${ }^{\text {b}}$ The combination of rs 8021276 AG genotype and rs8021276 GG genotype.

genetic susceptibility factor for liver cirrhosis. Although we observed some evidence of other SNPs, including rs7158733 and rs10146249, increasing liver cirrhosis risk, they were excluded in the final analyses according to the significance threshold $\left(\alpha_{\text {correct }}=1.87 \times 10^{-4}\right)$ in the present study. Thus, the potential role of genetic SNPs in the AT3 gene influencing liver cirrhosis risk should not be neglected.

To explore the effect of AT3 rs8021276 polymorphism on AFB1-related liver cirrhosis, AFB1DNA adducts and expression of AT3 of tissues samples with liver cirrhosis were examined. It was found that this polymorphism was correlated with increasing amount of DNA adducts and the downregulation of AT3 expression. A recent study has shown that this gene can modify DNA repair response to double strand damage of DNA [31]. The interactive analysis further indicated that AT3 rs8021276 polymorphism multiplicatively interacted with environmental variable AFB1 exposure, highlighting the possible role of this polymorphism in the predictive value for AFB1-induced liver cirrhosis. Collectively, these data imply that AT3 rs8021276 polymorphism may be linked to the lost or reduction of DNA repair ability via regulating AT3 expression. Therefore, it may display a vital role in the pathogenesis of liver cirrhosis related to AFB1 exposure.

For investigating the correlation between genetic SNPs and AFB1-related liver damage, it is very important to select sufficiently significant SNPs and elucidate AFB1 exposure levels [32-34]. In this study, we used a twostage and individually matched design for screening and validating significant SNP sites and avoiding the effects of known confounders (such as the infective status of $\mathrm{HBV}$ and $\mathrm{HCV}$ ). Results from multivariable and stratified analyses indicated that positive SNPs were significantly screened. Furthermore, confounders were effectively controlled and did not modify the relationship between the AT3 rs8021276 polymorphism and liver cirrhosis related to AFB1 exposure. Given that serum AAA marker is characterized by high stability and can reflect long-term exposure information of AFB1 [32], this marker was used to evaluate the AFB1 exposure status. Results also showed higher serum level of AAA was found in these cases with liver cirrhosis and increasing AAA level significant increased the risk of liver cirrhosis.

To conclude, our study firstly described the association between genetic polymorphisms in the AT3 gene and liver cirrhosis caused by AFB1 exposure, and our results provide some important evidence of AT3 rs 8021276 polymorphism as a biologic marker for estimating the risk of liver cirrhosis caused by AFB1 exposure. In view of the fact that AT3 is one of major DUBs in response to cellular physiology by regulating both cytosolic and nuclear processes $[10,31]$, the present study provides new data for identifying high-risk individuals, especially these with high risk factor AFB1 exposure. However, the main important limitations of our study were potential selection bias (resulting from the hospital-based design) and possible biased distribution of liver disease severity (e.g., the HBV DNA level). Additionally, the function analyses of AT3 rs8021276 polymorphism affecting the risk of AFB1-related liver cirrhosis, except for the effects of this polymorphism on AT3 expression and AFB1-DNA adducts, were not finished. Therefore, detailed functional 
A

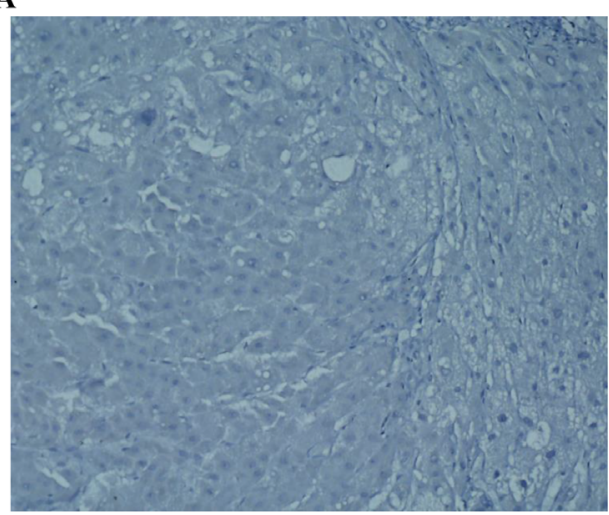

AT3 rs8021276-GG

C

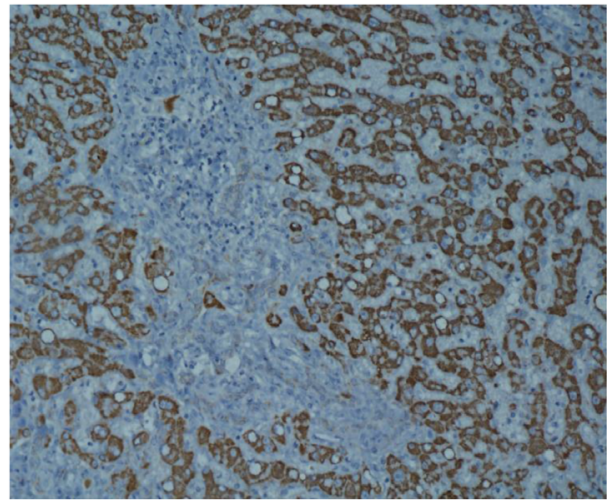

AT3 rs8021276-AA

$\mathbf{E}$

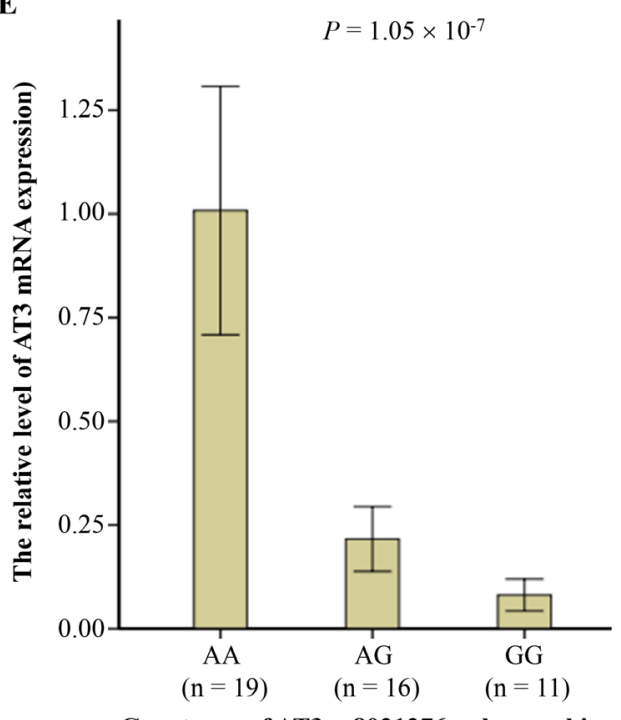

Genotypes of AT3 rs8021276 polymorphism
B

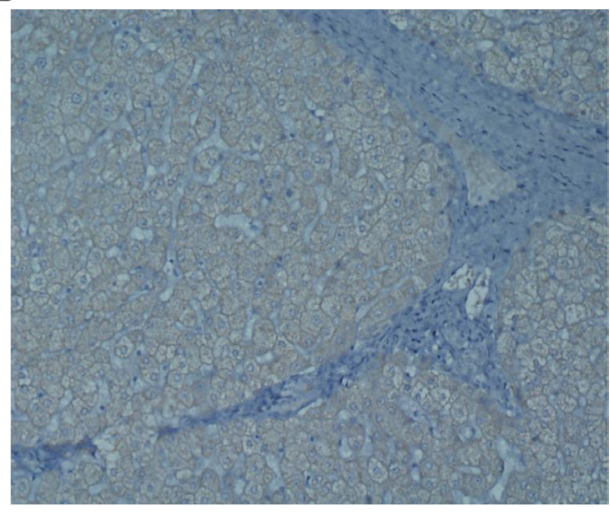

AT3 rs8021276-AG

D

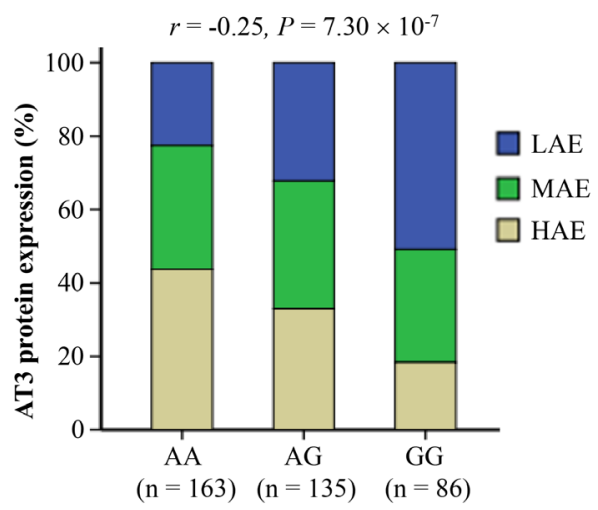

Genotypes of AT3 rs8021276 polymorphism

F

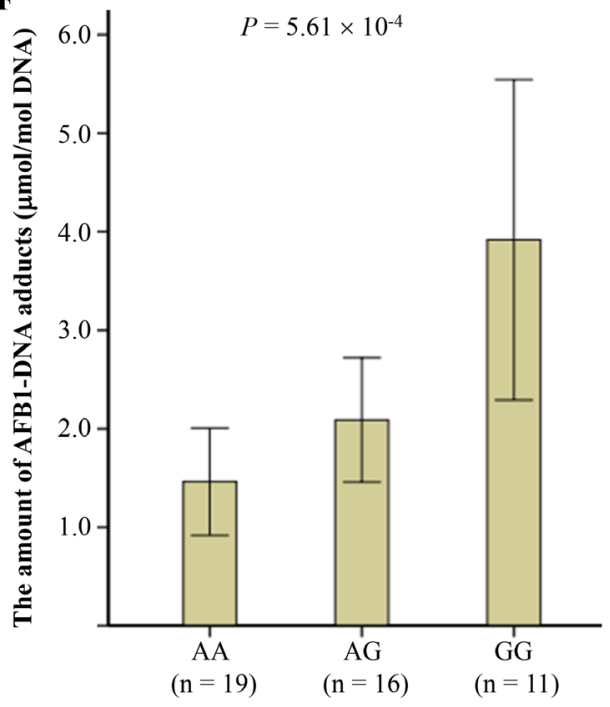

Genotypes of AT3 rs8021276 polymorphism

Figure 1: The ataxin-3 (AT3) rs8021276 polymorphism significantly correlated with AT3 expression and aflatoxin B1 (AFB1)-DNA adducts in the liver tissues with cirrhosis. (A-D) The level of AT3 protein in liver tissue samples $(n=384)$ was tested by immunohistochemistry (IHC) and scored using the IHC scores of IRS system (see Material and Methods). Representative images show that different expression levels were observed in liver tissues from cases with different AT3 rs8021276 genotypes (scale bars: $50 \mathrm{~mm})(\mathbf{A}-\mathbf{C})$. The association between AT3 rs8021276 genotypes and AT3 protein levels was evaluated by spearman correlation test (D). E-F, Total RNAs and DNAs were extracted from fresh liver tissues with cirrhosis $(n=46)$, and use to test the levels of AT3 mRNA expression $(\mathbf{E})$ and the amount of AFB1-DNA adducts (F) by TaqMan-PCR and comparative enzyme-linked immunosorbent assay. Data were analyzed using oneway ANOVA test (with Bonferroni correction). Abbreviations: LAE, low AT3 protein expression; MAE, medium AT3 protein expression; HAE, high AT3 protein expression. 
analyses combining AFB1 on the basis of a large samples may improve the present study.

\section{MATERIALS AND METHODS}

\section{Study population}

We utilized a hospital-based case-control study of AFB1-related liver cirrhosis in Bose, a knowledge high AFB1 exposure area from China. Liver cirrhosis patients who underwent liver biopsy in hospitals affiliated with Youjiang Medical University for Nationalities in Bose from January 2008 to December 2012 were utilized. Control individuals without clinic evidence of hepatic diseases were recruited from the general-health checkup center of the same hospitals, individual-matched (1:1 or $2: 1$ ) with cases by sex, age ( \pm 5 years), ethnicity, and $\mathrm{HBV}$ and $\mathrm{HCV}$ infection. All controls were surveyed to ascertain their willingness to participate in the study and to provide preliminary demographic data. In this study, a total of 384 cases with liver cirrhosis and 851 controls, representing $93 \%$ of eligible cases and $95 \%$ of eligible controls were interviewed and included the final analysis. Informed consent was obtained from each participant before inclusion in the study. Subject evaluation included a structured interview that elicited information on demographic characteristics (including age, race, smoking and drinking status, and detailed medical history for themselves and their families); collection of study samples; and a standardized clinical examination. At the same time, $5 \mathrm{ml}$ of peripheral blood was obtained for the analysis of AFB1 exposure and SNP genotypes along with demographic data. Forty-six fresh liver tissue specimens with liver cirrhosis were also collected for AT3 mRNA expression and AFB1-DNA adduct analysis. Among these subjects, we randomly selected 100-matched cases and controls to form the screening set and the remaining patients formed the validation set. This study was approved by the Institutional Ethics Committee of Youjiang Medical University for Nationalities, and was carried out in accordance with the approved guidelines (No. AYJM20071220).

\section{AFB1 exposure data}

In this study, AFB1 exposure information was valuated using serum AAA levels of peripheral blood as previously published [35]. For statistical analysis, values were logarithmically transformed and then were divided into three subgroups: low ( $<1.48 \mathrm{ln} \mathrm{fmol} / \mathrm{mg}$ ), medium (1.48-2.40 $\mathrm{ln} \mathrm{fmol} / \mathrm{mg})$, and high ( $>2.40 \mathrm{ln} \mathrm{fmol} / \mathrm{mg})$, according to the mean logit value of serum AAA among controls and cases.

\section{AFB1-DNA adducts assay}

The DNA was extracted from fresh liver tissues with liver cirrhosis for AFB1-DNA adduct analysis. AFB1-DNA adducts levels was tested using comparative enzyme-linked immunosorbent assay as our previously described [36, 37].

\section{SNP selection and genotyping}

In the screening study, we included 264 common (minor allele frequency $>0.1$ in Asians) SNPs located in AT3 gene. Genotyping was performed by using SNaPshot method (Applied Biosystems [ABI], Foster City, CA), according to the manufacturers' instructions. For genotypic analyses of SNPs, the controls and cases were genotyped at the same time, and duplicate test samples and two water samples (PCR negative controls) were included in each 96-well plate, with the technician blinded to the identity of the samples. The rate of concordant results in 100 duplicate samples was $>99 \%$. In the validation-stage study, three significant SNPs (rs8021276, rs7158733, and rs10146249) were genotyped by the TaqMan polymerase chain reaction (TaqMan-PCR) assays using the ABI 7900 System. Each PCR was carried out in a total volume of $5 \mu \mathrm{L}$ consisting of 1 ' Premix Ex Taq $^{\mathrm{TM}}$ (TaKaRa Biotechnology (Dalian) Co., Ltd., Dalian, China), $0.2 \mu \mathrm{M}$ of each probe and each primer (analyzing\# C_44789227_10, C_27204300_20, and C_30018528_10 for rs8021276, rs7158733, and rs10146249; cat\# 4351379, ABI), and 10-20 ng of genomic DNA. The PCR program had an initial denaturation step of $10 \mathrm{~min}$ at $95{ }^{\circ} \mathrm{C}$ followed by 40 cycles of $15 \mathrm{sec}$ at $95^{\circ} \mathrm{C}$ and $1 \mathrm{~min}$ at $60^{\circ} \mathrm{C}$. For quality control, controls were included in each run, and repeated genotyping and sequencing of a random $5 \%$ subset yielded $100 \%$ identical genotypes.

\section{Expression assays of AT3 protein}

The levels of AT3 protein in formalin-fixed biopsy tissue samples with liver cirrhosis $(n=384)$ was tested by IHC technique as our previously described [35, 36, 38], and scored using the IHC scores of IRS system [18]. To analyze, the IRS amount of AT3 protein was grouped into three levels: low (IRS value, $<4$ ), medium (IRS value, 4-8), and high expression (IRS value, $>8$ ).

\section{Expression assays of AT3 mRNA}

Total RNA was extracted from fresh tissues with liver cirrhosis using EZMA ${ }^{\text {TM }}$ MicroElute Total RNA Kit with DNase I (Omega, Norcross, GA) and corresponding first-strand cDNA was synthesized using RevertAidTM First Strand cDNA Synthesis Kit (Fermentas, Glen Burnie, MD). The relative quantitation of AT3 mRNA-expressing levels using the comparative CT method (2- ${ }^{-\Delta \Delta \mathrm{Ct}}$ method) 
was carried out by TaqMan-PCR (with an internal control UBC mRNA). The primers were: 5'-GAGGA TGAGA ATGGC AGAAG GA-3' and 5'-CCAGA AGGCT GCTGT AAAAA CG-3'for AT3 and 5'-GGGCA CTGGT TTTCT TTCCA-3' and 5'-CGCCG AGAAG GGACT ACTTT T-3' for UBC (Shanghai GeneCore BioTechnologies Co., Ltd., Shanghai, China) [35]. The probes were: 5'-FAM-AGTTA CTAGT GAAGA TTATC G-MGB-3' for AT3 and 5' - HEX-AGAGCGGAACAGGC-MGB-3' for UBC (Shanghai GeneCore BioTechnologies Co., Ltd.) [35]. PCR amplification was performed in a $25-\mu \mathrm{L}$ final reaction mixture containing $1 \times$ Premix Ex Taq ${ }^{\mathrm{TM}}$ (TaKaRa), $0.2 \mu \mathrm{M}$ of each probe, $0.2 \mu \mathrm{M}$ of each primer, and $1 \mu \mathrm{L}$ reverse transcription product with cDNAs. PCR reaction conditions comprised an initial step at $95^{\circ} \mathrm{C}$ for $2 \mathrm{~min}$, followed by 45 cycles at $95^{\circ} \mathrm{C}$ for $10 \mathrm{sec}$ and $60^{\circ} \mathrm{C}$ for $1 \mathrm{~min}$. Data analysis for the relative level of AT3 mRNA expression was performed with the Bio-Rad $\mathrm{iQ}^{\mathrm{TM}}$ Optical System Software Version 2.0.

\section{Statistical analysis}

The $\chi 2$ test, Student $t$ test, or one-way ANOVA test was used to test for differences between groups, demographic characteristics, AFB1-exposure information, and SNP genotypes. Conditional logistic regression was used to calculate ORs for risk of liver cirrhosis and their 95\% CIs. In this study, the additive model (treating genotype as an ordinal variable) was used to screen the main effects of 264 SNPs in the AT3 for liver cirrhosis risk. The correlation matrix-based method was used to correct for multiple testing and 2 -sided $P$ values smaller than 1.87 $\times 10^{-4}$ were considered significant for the main effects of SNPs in the screening stage. In the joint analysis stage of SNPs and AFB1 exposure, genotype frequencies in these groups were further adjusted for multiple comparisons using Bonferroni's method, and the significance threshold was lowered to $\alpha_{\text {correct }}=9.35 \times 10^{-5}$. All statistical analyses were done using the statistical package for social science (SPSS) version 18 (SPSS Institute, Chicago, IL).

\section{Abbreviations}

AT3, ataxin-3; rs8021276-AA, the homozygote of rs8021276 A alleles; rs8021276-GG, the homozygote of rs8021276 G alleles; rs8021276-AG, the heterozygote of rs8021276 G alleles; rs8021276-AG/GG, genotypes with rs8021276 A and G alleles.

\section{Author contributions}

W.-X.Z. performed immunohistochemistry and molecular biological experiments. H.-X.Y. and Y.-J.G. performed ELISA assays and data analysis. W.C., H.-X.Y. and Y.-J.G. obtained clinical samples and data collection. X.Q. partially designed the experimental plans. L.-X.D. supervised the project, designed experiments, analyzed results and wrote the manuscript.

\section{ACKNOWLEDGMENTS}

We thank Dr. Yuan-Feng Zhou and Prof. Yun Ma for sample collection and management; Dr. Hua Huang for molecular biochemical technique. We also thank all members of Department of Medical Test and Infective Control, Affiliated Hospital of Youjiang Medical College for Nationalities for their help.

\section{CONFLICTS OF INTEREST}

The authors declare no competing financial interests.

\section{FUNDING}

This research was supported in part by the National Natural Science Foundation of China (Nos. 81760502, $81572353,81372639,81472243,81660495$, and 81460423), the Innovation Program of Guangxi Municipal Education Department (Nos. 201204LX674 and 201204LX324), Innovation Program of Guangxi Health Department (No. Z2013781), the Natural Science Foundation of Guangxi (Nos. 2017JJF10001, 2017GXNSFAA198002, 2016GXNSFDA380003, 2015GXNSFAA139223, 2013GXNSFAA019251，2014GXNSFDA118021, and 2014GXNSFAA118144), Research Program of Guangxi "Zhouyue Scholar" (No. 2017-38), Research Program of Guangxi Specially-invited Expert (No. 2017-6th), Research Program of Guangxi Clinic Research Center of Hepatobiliary Diseases (No. AD17129025), and Open Research Program from Molecular Immunity Study Room Involving in Acute \& Severe Diseases in Guangxi Colleges and Universities (Nos. kfkt20160062 and kfkt20160063).

\section{REFERENCES}

1. Long XD, Yao JD, Yang Q, Huang CH, Liao P, Nong LG, Tang YJ, Huang XY, Wang C, Wu XM, Huang BC, Ban FZ, Zeng LX, et al. Polymorphisms of DNA repair genes and toxicological effects of aflatoxin B1 exposure. In: Aflatoxins: Food Sources, Occurrence and Toxicological Effects. Faulkner AG (ed.), New York Nova Science Publishers. 2014; 107-24.

2. Kensler TW, Roebuck BD, Wogan GN, Groopman JD. Aflatoxin: a 50-year odyssey of mechanistic and translational toxicology. Toxicol Sci. 2011; 120:S28-48. https://doi.org/10.1093/toxsci/kfq283.

3. Kucukcakan B, Hayrulai-Musliu Z. Challenging Role of Dietary Aflatoxin B1 Exposure and Hepatitis B Infection on Risk of Hepatocellular Carcinoma. Open Access Maced J Med Sci. 2015; 3:363-9. https://doi.org/10.3889/ oamjms.2015.032. 
4. Chu YJ, Yang HI, Wu HC, Liu J, Wang LY, Lu SN, Lee MH, Jen CL, You SL, Santella RM, Chen CJ. Aflatoxin B1 exposure increases the risk of cirrhosis and hepatocellular carcinoma in chronic hepatitis B virus carriers. Int J Cancer. 2017; 141:711-20. https://doi.org/10.1002/ijc.30782.

5. Aydin M, Aydin S, Bacanli M, Basaran N. Aflatoxin levels in chronic hepatitis B patients with cirrhosis or hepatocellular carcinoma in Balikesir, Turkey. J Viral Hepat. 2015; 22:926-35. https://doi.org/10.1111/jvh.12410.

6. El-Shanawani FM, Abdel-Hadi AA, Abu Zikri NB, Ismail A, El-Ansary M, El-Raai A. Clinical significance of aflatoxin, mutant P53 gene and sIL-2 receptor in liver cirrhosis and hepatocellular carcinoma. J Egypt Soc Parasitol. 2006; 36:221-39.

7. Evers MM, Tran HD, Zalachoras I, Pepers BA, Meijer OC, den Dunnen JT, van Ommen GJ, Aartsma-Rus A, van RoonMom WM. Ataxin-3 protein modification as a treatment strategy for spinocerebellar ataxia type 3: removal of the CAG containing exon. Neurobiol Dis. 2013; 58:49-56. https://doi.org/10.1016/j.nbd.2013.04.019.

8. Sheneef A, Esmat MM, Mohammad AN, Mahmoud AA, Moghazy HM, Noureldin AK. Interleukin-10 and Interferon Gamma Gene Polymorphisms and Hepatitis C VirusRelated Liver Cirrhosis Risk. J Interferon Cytokine Res. 2017; 37:175-80. https://doi.org/10.1089/jir.2016.0106.

9. Albrecht M, Golatta M, Wullner U, Lengauer T. Structural and functional analysis of ataxin-2 and ataxin-3. Eur $\mathrm{J}$ Biochem. 2004; 271:3155-70. https://doi.org/10.1111/ j.1432-1033.2004.04245.x.

10. Evers MM, Toonen LJ, van Roon-Mom WM. Ataxin-3 protein and RNA toxicity in spinocerebellar ataxia type 3: current insights and emerging therapeutic strategies. Mol Neurobiol. 2014; 49:1513-31. https://doi.org/10.1007/ s12035-013-8596-2.

11. Switonski PM, Fiszer A, Kazmierska K, Kurpisz M, Krzyzosiak WJ, Figiel M. Mouse ataxin-3 functional knockout model. Neuromolecular Med. 2011; 13:54-65. https:// doi.org/10.1007/s12017-010-8137-3.

12. Santambrogio C, Frana AM, Natalello A, Papaleo E, Regonesi ME, Doglia SM, Tortora P, Invernizzi G, Grandori $\mathrm{R}$. The role of the central flexible region on the aggregation and conformational properties of human ataxin-3. FEBS J. 2012; 279:451-63. https://doi.org/10.1111/j.17424658.2011.08438.x.

13. Sacco JJ, Yau TY, Darling S, Patel V, Liu H, Urbe S, Clague MJ, Coulson JM. The deubiquitylase Ataxin-3 restricts PTEN transcription in lung cancer cells. Oncogene. 2014; 33:4265-72. https://doi.org/10.1038/onc.2013.512.

14. Zeng LX, Tang Y, Ma Y. Ataxin-3 expression correlates with the clinicopathologic features of gastric cancer. Int J Clin Exp Med. 2014; 7:973-81.

15. Warrick JM, Morabito LM, Bilen J, Gordesky-Gold B, Faust LZ, Paulson HL, Bonini NM. Ataxin-3 suppresses polyglutamine neurodegeneration in Drosophila by a ubiquitin-associated mechanism. Mol Cell. 2005; 18:37-48. https://doi.org/10.1016/j.molcel.2005.02.030.

16. Pereira FS, Monte TL, Locks-Coelho LD, Silva AS, Barsottini O, Pedroso JL, Cornejo-Olivas M, Mazzetti P, Godeiro C, Vargas FR, Lima MA, van der Linden H Jr, Toralles MB, et al. ATXN3, ATXN7, CACNA1A, and RAI1 Genes and Mitochondrial Polymorphism A10398G Did Not Modify Age at Onset in Spinocerebellar Ataxia Type 2 Patients from South America. Cerebellum. 2015; 14:728-30. https://doi.org/10.1007/s12311-015-0666-8.

17. Brennan P. Gene-environment interaction and aetiology of cancer: what does it mean and how can we measure it? Carcinogenesis. 2002; 23:381-7.

18. Friedrichs K, Gluba S, Eidtmann H, Jonat W. Overexpression of p53 and prognosis in breast cancer. Cancer. 1993; 72:3641-7.

19. Lun-Gen L. Antiviral Therapy of Liver Cirrhosis Related to Hepatitis B Virus Infection. J Clin Transl Hepatol. 2014; 2:197-201. https://doi.org/10.14218/JCTH.2014.00022.

20. Zhou WC, Zhang QB, Qiao L. Pathogenesis of liver cirrhosis. World J Gastroenterol. 2014; 20:7312-24. https:// doi.org/10.3748/wjg.v20.i23.7312.

21. Lin J, Wu JF, Zhang Q, Zhang HW, Cao GW. Virus-related liver cirrhosis: molecular basis and therapeutic options. World J Gastroenterol. 2014; 20:6457-69. https://doi. org/10.3748/wjg.v20.i21.6457.

22. Villar S, Ortiz-Cuaran S, Abedi-Ardekani B, Gouas D, Nogueira da Costa A, Plymoth A, Khuhaprema T, Kalalak A, Sangrajrang S, Friesen MD, Groopman JD, Hainaut P. Aflatoxin-induced TP53 R249S mutation in hepatocellular carcinoma in Thailand: association with tumors developing in the absence of liver cirrhosis. PLoS One. 2012; 7:e37707. https://doi.org/10.1371/journal.pone.0037707.

23. Kuniholm MH, Lesi OA, Mendy M, Akano AO, Sam O, Hall AJ, Whittle H, Bah E, Goedert JJ, Hainaut P, Kirk GD. Aflatoxin exposure and viral hepatitis in the etiology of liver cirrhosis in the Gambia, West Africa. Environ Health Perspect. 2008; 116:1553-7. https://doi.org/10.1289/ ehp.11661.

24. Bhandari PC, Bhandari B. Aflatoxin and Indian Childhood Cirrhosis. Indian Pediatr. 1980; 17:593-6.

25. Tarhuni A, Guyot E, Rufat P, Sutton A, Bourcier V, Grando V, Ganne-Carrie N, Ziol M, Charnaux N, Beaugrand M, Moreau R, Trinchet JC, Mansouri A, et al. Impact of cytokine gene variants on the prediction and prognosis of hepatocellular carcinoma in patients with cirrhosis. J Hepatol. 2014; 61:342-50. https://doi.org/10.1016/j. jhep.2014.04.011.

26. Corchado S, Marquez M, Montes de Oca M, Romero-Cores P, Fernandez-Gutierrez C, Giron-Gonzalez JA. Influence of Genetic Polymorphisms of Tumor Necrosis Factor Alpha and Interleukin 10 Genes on the Risk of Liver Cirrhosis in HIV-HCV Coinfected Patients. PLoS One. 2013; 8:e66619. https://doi.org/10.1371/journal.pone.0066619. 
27. Zimmermann T, Otto C, Hoppe-Lotichius M, Biesterfeld S, Lautem A, Knaak M, Zimmermann A, Barreiros AP, Heise M, Schattenberg JM, Sprinzl MF, Galle PR, Otto $\mathrm{G}$, et al. Risk factors in patients with rapid recurrent hepatitis $\mathrm{C}$ virus-related cirrhosis within 1 year after liver transplantation. Transplant Proc. 2009; 41:2549-56. https:// doi.org/10.1016/j.transproceed.2009.06.120.

28. Nahon P, Sutton A, Rufat P, Simon C, Trinchet JC, Gattegno L, Beaugrand M, Charnaux N. Chemokine system polymorphisms, survival and hepatocellular carcinoma occurrence in patients with hepatitis $\mathrm{C}$ virus-related cirrhosis. World J Gastroenterol. 2008; 14:713-9.

29. Ge F, Chen W, Qin J, Zhou Z, Liu R, Liu L, Tan J, Zou T, Li H, Ren G, Chen C. Ataxin-3 like (ATXN3L), a member of the Josephin family of deubiquitinating enzymes, promotes breast cancer proliferation by deubiquitinating Kruppel-like factor 5 (KLF5). Oncotarget. 2015; 6:21369-78. https://doi. org/10.18632/oncotarget.4128.

30. Long Z, Chen Z, Wang C, Huang F, Peng H, Hou X, Ding D, Ye W, Wang J, Pan Q, Li J, Xia K, Tang B, et al. Two novel SNPs in ATXN3 3' UTR may decrease age at onset of SCA3/MJD in Chinese patients. PLoS One. 2015; 10:e0117488. https://doi.org/10.1371/journal.pone.0117488.

31. Pfeiffer A, Luijsterburg MS, Acs K, Wiegant WW, Helfricht A, Herzog LK, Minoia M, Bottcher C, Salomons FA, van Attikum H, Dantuma NP. Ataxin-3 consolidates the MDC1-dependent DNA double-strand break response by counteracting the SUMO-targeted ubiquitin ligase RNF4. EMBO J. 2017; 36:1066-83. https://doi.org/10.15252/ embj.201695151.

32. Huang XY, Luo CY, Wu XM, Yao JG, Wang C, Huang BC, Lu J, Wang XZ, Zhang TQ, Xia Q, Long XD. The serum microRNA expression modified the genic toxicity caused by aflatoxin B1. In: Aflatoxin-Control, Analysis, Detection and Health Risks. Abdulra L (ed.), InTech. 2017; Chapter 10:20928. https://doi.org/10.5772/intechopen.68419.
33. Lu J, Wang XZ, Zhang TQ, Huang XY, Yao JG, Wang C, Wei ZH, Ma Y, Wu XM, Luo CY, Xia Q, Long XD. Prognostic significance of XRCC4 expression in hepatocellular carcinoma. Oncotarget. 2017; 8:87955-70. https://doi.org/10.18632/oncotarget.21360.

34. Wu XM, Xi ZF, Liao P, Huang HD, Huang XY, Wang C, Ma Y, Xia Q, Yao JG, Long XD. Diagnostic and prognostic potential of serum microRNA-4651 for patients with hepatocellular carcinoma related to aflatoxin B1. Oncotarget. 2017; 8:81235-49. https://doi.org/10.18632/ oncotarget.16027.

35. Long XD, Yao JG, Zeng Z, Ma Y, Huang XY, Wei ZH, Liu M, Zhang JJ, Xue F, Zhai B, Xia Q. Polymorphisms in the coding region of $\mathrm{X}$-ray repair complementing group 4 and aflatoxin B1-related hepatocellular carcinoma. Hepatology. 2013; 58:171-81. https://doi.org/10.1002/hep.26311.

36. Long XD, Zhao D, Wang C, Huang XY, Yao JG, Ma Y, Wei ZH, Liu M, Zeng LX, Mo XQ, Zhang JJ, Xue F, Zhai B, et al. Genetic polymorphisms in DNA repair genes XRCC4 and XRCC5 and aflatoxin B1-related hepatocellular carcinoma. Epidemiology. 2013; 24:671-81. https://doi. org/10.1097/EDE.0b013e31829d2744.

37. Long XD, Ma Y, Zhou YF, Yao JG, Ban FZ, Huang YZ, Huang BC. XPD codon 312 and 751 polymorphisms, and AFB1 exposure, and hepatocellular carcinoma risk. BMC Cancer. 2009; 9:400. https://doi.org/10.1186/1471-2407-9-400.

38. Long XD, Ma Y, Zhou YF, Ma AM, Fu GH. Polymorphism in xeroderma pigmentosum complementation group C codon 939 and aflatoxin B1-related hepatocellular carcinoma in the Guangxi population. Hepatology. 2010; 52:1301-9. https://doi.org/10.1002/hep.23807. 